\title{
Interdisciplinary Peripartum Management of Acute Respiratory Distress Syndrome with Extracorporeal Membrane Oxygenation - a Case Report and Literature Review
}

\author{
Extrakorporale Membranoxygenierung für das interdisziplinäre peripartale Management \\ von schwerem akutem Atemnotsyndrom - ein Fallbericht mit Literaturübersicht
}

Authors

Affiliations
J. Weyrich ${ }^{1}$, R. Bogdanski ${ }^{2}$, J. U. Ortiz ${ }^{1}$, B. Kuschel ${ }^{1}$, K. T. M. Schneider ${ }^{1}$, S. M. Lobmaier ${ }^{1}$

${ }^{1}$ Frauenklinik und Poliklinik der Technischen Universität München, München

${ }^{2}$ Klinik für Anaesthesiologie der Technischen Universität München

Key words
ECMO
ARDS
uterine rupture
vaginal birth after
2 Caesarean sections
TRALI
- SIRS
Schlüsselwörter
ECMO
SARS
- Uterusruptur
vaginale Entbindung
nach 2 Kaiserschnitten
TRALI
- SIRS

received $\quad 29.8 .2015$

revised $\quad 2.11 .2015$

accepted $\quad 22.11 .2015$

Bibliography

DOI http://dx.doi.org/

10.1055/s-0041-110132

Geburtsh Frauenheilk 2016; 76:

273-276 @ Georg Thieme

Verlag KG Stuttgart · New York . ISSN 0016-5751

\section{Correspondence \\ Dr. J. Weyrich \\ Frauenklinik und Poliklinik \\ der Technischen Universität \\ München \\ Ismaninger Straße 22 \\ 81675 München \\ joy.weyrich@yahoo.de}

\begin{abstract}
$\nabla$

Extracorporeal membrane oxygenation (ECMO) is increasingly used for the management of acute severe cardiac and respiratory failure. One of the indications is acute respiratory distress syndrome (ARDS) for which, in some severe cases, ECMO represents the only possibility to save lives. We report on the successful long-term use of ECMO in a postpartum patient with recurrent pulmonary decompensation after peripartum uterine rupture with extensive blood loss.
\end{abstract}

\section{Introduction \\ $\nabla$}

Obstetrical patients rarely end up at intensive care units (ICU). Excessive postpartal bleeding and hypertensive disorders are the most common reasons for ICU admissions.

Almost 10 to $15 \%$ of ICU patients and up to $20 \%$ of mechanically ventilated patients meet criteria for acute respiratory distress syndrome (ARDS) [1]. Large blood loss and pre-existing bad pulmonary conditions represent two risk factors for ARDS. This acute, diffuse, inflammatory lung injury often ends up in long-term intensive care stays. Numerous other complications may follow. We describe the outcome and emerging problems of a complicated delivery with postpartal ARDS which needed emergency admission to ICU and a long-term therapy with extracorporeal membrane oxygenation (ECMO) for a total of 50 days.

\section{Case Report \\ $\nabla$}

A 34-year old female patient from Somalia (gravida 6 , para 5) presented at 38 weeks of gestation at our hospital for birth registration. She reported

\section{Zusammenfassung \\ $\nabla$}

Extrakorporale Membranoxygenierung (ECMO) wird immer häufiger für das Management von schwerem Herz- und Lungenversagen eingesetzt. Das schwere akute Atemnotsyndrom (SARS) kann dafür ursächlich sein. In besonders schweren Fällen stellt die ECMO die einzige Möglichkeit dar, Leben zu retten. Wir berichten hier über den erfolgreichen postpartalen Einsatz von ECMO bei einer Patientin mit rekurrierender pulmonaler Dekompensation nach Uterusruptur mit schwerem Blutverlust während der Geburt.

three vaginal deliveries in Somalia and had two Caesarean sections (CS) in Germany. She roughly mentioned "lung problems" in her medical past which were supposed to be resolved. Her exercise capacity seemed unaffected. Exact details of the medical history and previous operations were blurred by the patient (no clear information about which hospitals had been involved were given). The ultrasound examination showed a normal fetus growth with normal Doppler-findings and a normal amniotic fluid index. During the general examination she presented signs of preeclampsia (increased blood pressure (>160/100 mmHg), protein/creatinine ratio of $900 \mathrm{mg} / \mathrm{g}$ ). Therefore the medical indication for induction of labour was explained to the patient. Partly due to religious convictions the patient planned to have more children in the future, so spontaneous labour instead of third Caesarean section was discussed. Aware of increased risk for uterine rupture the patient decided for spontaneous delivery and gave her informed consent.

The vaginal examination showed no female genital mutilation, a soft cervix, approximately $1 \mathrm{~cm}$ long and with a uterine orifice open to $2 \mathrm{~cm}$, the child's head fixed. First an induction trial with an 
extraamniotic Foley balloon catheter was made. As the balloon did not stay in place however, $1 \mathrm{mg}$ of prostaglandin gel was used intravaginally at Bishopscore 5.

During the first stage of labour at $3 \mathrm{~cm}$ cervical dilatation a prolapse of the child's arm occurred. While the patient was getting prepared for CS fetal bradycardia lead into emergency CS. Intraoperatively a large rupture of the anterior uterine wall became apparent. After safe delivery of an initially limp baby (Apgar 2/ 10/10, pH 6.99) with direct transfer to the paediatricians this rupture could be sutured with single stiches in the area of uterotomia and finally with 2 layers of continuous stitches. Due to excessive intrapartum bleeding (haemoglobin $5.4 \mathrm{mg} / \mathrm{dl}$, blood loss approximately 1.5 litres) the patient was transferred to intensive care unit (ICU). There she was stabilized with blood transfusion. A perioperative antibiotic prophylaxis (cefuroxime) was initiated. The patient was transferred to the obstetric ward 24 hours after CS. On day 2 after CS the patient suffered more and more from pronounced dyspnea. The cardiologic examination showed normal results and pulmonary embolism was excluded by CT scan. However, the CT showed bipulmonary infiltrates and shadows. On suspicion of pneumonia the patient was treated with a broad-spectrum antibiotic (imipenem). In the further course her general condition worsened so that at one point when the patient suffered from massive dyspnea the resuscitation team was alerted. When the team arrived the patient was unconscious and with low heart rate which became an asystolia during the intubation procedure and lead to resuscitation. CPR was performed for 2 minutes during the intubation procedure. Saturation at this time was not documented. The blood gas analysis afterwards showed $\mathrm{pH} 7.375, \mathrm{pO}_{2} 171.9 \mathrm{mmHg}, \mathrm{BE} 2.2$ and lactate $0.9 \mathrm{mmol} / \mathrm{l}$. Again we admitted the patient to ICU at day 5 after CS.

During the following days the patient underwent lung protective ventilation with low tidal volumes (4-6 ml $/ \mathrm{kgBW}$ ) in relation to the patient's ideal body weight, plateau pressures were below $30 \mathrm{~cm}^{2} \mathrm{H}_{2} \mathrm{O}$. PEEP was adjusted between 10 and $16 \mathrm{~cm}^{2} \mathrm{H}_{2} \mathrm{O}$. Prone positioning of the patient was tried several times, but oxygenation was not improved (non responder/recruiter). Prone positioning was kept for $14-16 \mathrm{~h}$; during that period the patient required four cardiopulmonary resuscitations due to recurrent bradycardia of uknown origin. Bradycardia and asytolia occurred reflectory since the first day in our ICU for example after coughing of the patient, after mouth care or when changing tubus position or when performing prone positioning. At this point the patient was not hypoxic. $\mathrm{FiO}_{2}$ was between 0.5 to 0.7 and $\mathrm{pO}_{2}$ never dropped below $70 \mathrm{mmHg}$. The patient was treated with atropin and/or epinephrine when this happened and an external pacing was placed and changed to a transjugular pacer on day 6 . At day ten decarboxylation became suddenly worse under prone positioning ( $\mathrm{pH} 6.965, \mathrm{pCO}_{2} 182 \mathrm{mHg}, \mathrm{pO}_{2} 111.2 \mathrm{mmHg}$ ) and we deciced to perform a VV-ECMO and a tracheotomy. We used a VV-ECMO for the main problem of decarboxylation and oxygenation. VV ECMO flow was up to $5 \mathrm{l} / \mathrm{min}$ and this was sufficient for oxygenation, too. A VA ECMO was not used because of a good cardiac function seen in repeated TEEs and TTEs.

During the installation of ECMO-cannulas the transjugular pacer was removed because this vascular access was needed for the ECMO canula und we switched again to an external pacer. The external pacer was needed until day 24 after ICU admission (day 14 after VV ECMO). Then the patient's condition became more stable and no more bradycardias came to pass. Anticoagulation was sustained with a continuous infusion of unfractionated hep- arin, titrated to the plasma PTT (1.5 times normal). Until then, multiple microbiological probes from blood and bronchoalveolar fluid showed no evidence of any bacterial, viral or fungal infection.

At day 19 after starting ECMO therapy the microbiological testing of blood cultures revealed for the first time pathogens (klebsiella oxytoca). We hypothesized a bacterial contamination of the ECMO circuit because of a fibrinogen loss and spontaneous bleeding from the bladder and from vascular punctures in the previous days. The infection was treated with antibiotics (first piperacillin plus tazobactam, then meropenem plus vancomycin) and by changing the oxygenator and the ECMO circuit, except the cannulas. The strong bladder bleeding required a cystoscopic-guided laser coagulation. Overall, the patient needed 58 units of stored blood. During the ECMO treatment the maximum creatininkinase level was $250 \mathrm{U} / 1$. ECG did not show abnormalities at any time. After 50 days the patient could be weaned from ECMO. The patient received assisted spontaneous breathing for a few more days and the tracheostoma was closed at day 88 after ICU admission. The patient was discharged home after 115 days of ICU treatment without cardiopulmonary or neurological deficits.

During her ICU stay, the medical documentation could be provided. Years ago the patient had undergone multiple pulmonary problems such as atypic pneumonia, chronic bronchitis, and a lobectomy of the lower lobe of one lung one year before the delivery. Furthermore, we found out that our patient required intensive care during her second last pregnancy. A community acquired pneumonia during the third trimester of pregnancy ended in ARDS together with renal failure and necessitated intubation, dialysis and emergency CS at 34 weeks of gestation. The last pregnancy showed a very similar course. After an induction of labour because of oligohydramnios the patient developed a restrictive ventilation disorder. It ended in secondary Caesarean section at 40th week of pregnancy and a transfer to ICU for invasive ventilation therapy in total for 11 days again for ARDS of unknown origin.

The patient was seeking intentionally to mislead us by providing false information regarding the aforementioned complications as a new pregnancy was not advised after the second last birth due to maternal health reasons.

Further family planning was discussed with the patient and her husband. We strongly recommended sterilisation or safe contraception. Medical visit at 6 months after discharge was without pathological findings. Mother and baby are in good health.

\section{Discussion}

This case reports on four rare complications during labour and postpartum period: the occurrence of arm prolapse, uterus rupture after two CS, postpartum haemorrhage (PPH) followed by ARDS. And finally we report the successful use of ECMO for circulatory support and for the treatment of acute respiratory distress in a postpartum situation.

Previous studies have reported a general rate of $1 / 5700$ to $1 /$ 20000 for uterus rupture in unscarred pregnant uterus [2-4]. The overall incidence of uterine rupture in women with a prior Caesarean delivery varies between 0.3 to 1 percent [5-7]. A recent large meta-analysis found an incidence of $0.7 \%$ for uterus rupture/dehiscence in women attempting a vaginal birth after one CS (VBAC-1) [7]. Furthermore, several series showed a general rate of $1.36 \%$ of uterine rupture during/after vaginal birth after 
two CS (VBAC-2) [8-12]. Although the uterine rupture rate of VBAC-2 is statistically higher than VBAC-1, it should not be forgotten that the absolute rate is very low. This should be kept in mind for patient counselling. In addition, the overall success rate of vaginal delivery after one or two CS is high so that an achievement is possible in $76.5 \%$ and $71.1 \%$, respectively [13].

The greatest concern about a trial of labour after a previous CS is a rupture of the scarred uterus. Whereby it should be mentioned that women with induction of labour were more likely to experience uterine rupture or dehiscence than women with spontaneous labour. Therefore, a labour induction indication after CS must be strictly defined. Some factors are important for a high success rate: A previous history of vaginal delivery and a favourable Bishop score are significant. The success rate is between $91 \%$ for women with favourable Bishop score and a prior vaginal delivery, and $45 \%$ for women with no prior vaginal delivery and an unfavourable Bishop score. For women with no prior previous vaginal delivery but favourable Bishop score a general rate of $69 \%$ successful induction was found [14]. The rupture rate of previously scarred uterus in a large prospective study is $0.4 \%$ with spontaneous labour versus $1 \%$ with labour induction [15]. These results show that labour induction after CS is possible and clinically justifiable - but, it should only be attempted in appropriately equipped institutions.

ICU admissions during pregnancy and peripartal period have a low incidence of $<1 \%[16,17]$. Among those patients, the most common causes are PPH and hypertensive disorders. Respiratory failure represents a very rare complication. Differential diagnosis includes pulmonary edema (mostly caused by tocolytic therapy), pneumonia, aspiration, and pulmonary embolism.

In this case, none of the above mentioned pathologies were responsible for the postpartum ARDS. To our opinion, ARDS in this patient was the result of serious tissue injury caused by the uterus rupture with massive blood loss and blood cell transfusion. In our case review the PPH was amplified by the large uterine rupture. The general rate of $1-2.9 \%$ of PPH is set in literature [18]. Like in this case serious tissue injury can cause systemic inflammatory response syndrome (SIRS). This is a life threatening posttraumatic complication which is characterized by fever, tachycardia, and tachypnea. These symptoms may resemble a sepsis. Cellular lesion releases mitochondrial endogenous "damage/danger associated molecular patterns" (DAMPs) that activate the immune system. Mitochondria are evolutionary endosymbionts that were derived from bacteria and so bear bacterial molecular motifs. Zhang et al. [19] found that mitochondrial DAMP is released by severe trauma in a similar way that bacterial DNA (PAMPs, pathogen-associated molecular patterns) is released following sepsis. Both use the toll-like receptor-9 (TLR9) to activate neutrophils through activation of p38 MAP kinase (MAPK) enzyme. Similarly, formylated peptides released from bacteria and mitochondria in these settings attract neutrophils by the process of chemotaxis to sites of inflammation and injury through formyl peptide receptor-1 (FPR1) [20]. In both cases, the outcome may be acute lung injury, as part of the SIRS.

On the other hand, the most frequent and severe complication of multiple blood transfusions is the transfusion-related acute lung injury (TRALI). The current pathogenic concepts hold that proinflammatory mediators present in transfused blood products are responsible for the initiation of TRALI [21]. Lee and collegues [22] hypothesized that mitochondrial (mt)DNA DAMPs are present in blood transfusion products, which may be important in the initiation of TRALI. They extracted DNA from samples of packed red blood cells, fresh frozen plasma (FFP), and platelets procured from their local blood bank. The results showed a range of mtDNA DAMPs in all blood components measured, with FFP displaying the largest variation and they concluded that mtDNA DAMPs are present in packed red blood cells, FFP, and platelets may be mediators of TRALI.

So in this case, the combination of tissue injury by the uterine rupture and the postpartum haemorrhage, which occurs generally in 1 to $5 \%$ of deliveries [23], has led to a severe ARDS in a patient with pre-existing bad pulmonary status.

ECMO often represents the last resort for serious acute respiratory distress, although a long-term therapy can lead to life-threatening complications such as haemorrhage and infections. In literature we found little mention of ECMO being used to manage peripartum patients with massive bleeding [24,25]. Both cases describe the use of ECMO for a short duration (150 respectively 72 hours). In our case the use of ECMO lasted for 50 days which represents an exceptionally long duration compared to literature [24-27].

Others reasons which can lead to ECMO in obstetrical patients are peripartum cardiomyopathy [28], amniotic fluid embolism [29] and transfusion-related acute lung injury [30]. In these cases ECMO lasted 40 to 150 hours and ended each time in a complete recovery of the patient. Main complications of ECMO are bleeding, thromboembolism, cannulation related problems and heparin-induced thrombocytopenia. Bleeding is the most common complication (30 to 40 percent) of ECMO. In our case even a urological intervention was necessary.

In conclusion, this case report includes an extraordinary sequence of unfortunate circumstances: Beginning with the need of induction of labour due to preeclampsia (with 2 previous Caesarean sections), arm prolapse during delivery in a multiparous patient, fetal bradycardia most likely due to uterine rupture followed by emergency Caesarean section with postpartum haemorrhage. This all followed by deterioration of maternal pulmonary and general condition resulting in ICU admission, consequently several manoeuvres of cardiopulmonary resuscitations and ECMO therapy for almost 2 months. Each of these risk factors is associated with an increased risk of mortality. Nevertheless, our patient could be dismissed in good general condition.

This particular case shows that induction of labour after two prior Caesarean deliveries might be dangerous although newer data showed that labour induction outcomes are similar regardless of whether women have had one or two CS [31]. An early clinical registration of the future mother should be gold standard. It allows obstetricians to identify high-risk pregnancies, take the necessary precautions and might improve the general outcome of mother and child. And finally we can demonstrate that ECMO support for severe respiratory failure in postpartum patients is possible and allows a full recovery even after a long-term therapy with complications.

\section{Conflict of Interest}

$\nabla$

None. 


\section{References}

1 Frutos-Vivar F, Nin N, Esteban A. Epidemiology of acute lung injury and acute respiratory distress syndrome. Curr Opin Crit Care 2004; 10: 1-6

2 Dow M, Wax JR, Pinette MG et al. Third-trimester uterine rupture without previous cesarean: a case series and review of the literature. Am J Perinatol 2009; 26: 739-744

3 Porreco RP, Clark SL, Belfort MA et al. The changing specter of uterine rupture. Am J Obstet Gynecol 2009; 200: 269.e1-269.e4

4 Miller DA, Goodwin TM, Gherman RB et al. Intrapartum rupture of the unscarred uterus. Obstet Gynecol 1997; 89: 671-673

5 Guise JM, Denman MA, Emeis C et al. Vaginal birth after cesarean: new insights on maternal and neonatal outcomes. Obstet Gynecol 2010; 115: $1267-1278$

6 National Institutes of Health Consensus Development Conference Panel. National Institutes of Health Consensus Development conference statement: vaginal birth after cesarean: new insights March 8-10, 2010. Obstet Gynecol 2010; 115: 1279-1295

7 Rossi AC, Prefumo F. Pregnancy outcomes of induced labour in women with previous cesarean section: a systematic review and meta-analysis. Arch Gynecol Obstet 2014

8 Macones GA, Cahill A, Pare E et al. Obstetric outcomes in women with two prior cesarean deliveries: is vaginal birth after cesarean delivery a viable option? Am J Obstet Gynecol 2005; 192: 1223-1228; discussion $1228-1229$

9 Landon MB, Spong CY, Thom E et al. Risk of uterine rupture with a trial of labor in women with multiple and single prior cesarean delivery. Obstet Gynecol 2006; 108: 12-20

10 Spaans WA, van der Vliet LM, Röell-Schorer EA et al. Trial of labour after two or three previous caesarean sections. Eur J Obstet Gynecol Reprod Biol 2003; 110: 16-19

11 Caughey AB, Shipp TD, Repke JT et al. Rate of uterine rupture during a trial of labor in women with one or two prior caesarean deliveries. Am J Obstet Gynecol 1999; 181: 872-876

12 Miller DA, Diaz FG, Paul RH. Vaginal birth after cesarean: a 10-year experience. Obstet Gynecol 1994; 84: 255-258

13 Tahseen S, Griffiths M. Vaginal birth after two caesarean sections (VBAC-2) - a systemic review with meta-analysis of success rate and adverse outcomes of VBAC-2 versus VBAC-1 and repeat (third) caesarean sections. BJOG 2010; 117: 5-19

14 Grobman WA, Gilbert S, Landon MB et al. Outcomes of induction of labor after one prior cesarean. Obstet Gynecol 2007; 109: 262-269

15 Landon MB, Hauth JC, Leveno KJ et al. Maternal and perinatal outcomes associated with a trial of labor after prior cesarean delivery. N Engl J Med 2004; 351: 2581-2589

16 Vasquez DN, Estenssoro E, Canales HS et al. Clinical characteristics and outcomes of obstetric patients requiring ICU admission. Chest 2007; 131: $718-724$
17 Pollock W, Rose L, Dennis CL. Pregnant and postpartum admissions to the intensive care unit: a systematic review. Intensive Care Med 2010; 36: $1465-1474$

18 Callaghan WM, Kuklina EV, Berg CJ. Trends in postpartum hemorrhage: United States, 1994-2006. Am J Obstet Gynecol 2010; 202: 353.e1-353. e6

19 Zhang $Q$, Raoof $M$, Chen $Y$ et al. Circulating mitochondrial DAMPs cause inflammatory responses to injury. Nature 2010; 464: 104-107

20 Manfredi AA, Rovere-Querini P. The mitochondrion - a Trojan horse that kicks off inflammation? N Engl J Med 2010; 362: 2132-2134

21 Land WG. Transfusion-related acute lung injury: the work of DAMPs. Transfus Med Hemother 2013; 40: 3-13

22 Lee YL, King MB, Gonzalez RP et al. Blood transfusion products contain mitochondrial DNA damage-associated molecular patterns: a potential effector of transfusion-related acute lung injury. J Surg Res 2014; 191: 286-289

23 Lu MC, Fridman M, Korst LM et al. Variations in the incidence of postpartum hemorrhage across hospitals in California. Matern Child Health J 2005; 9: 297-306

24 Reyftmann L, Morau E, Dechaud H et al. Extracorporeal membrane oxygenation therapy for circulatory arrest due to postpartum hemorrhage. Obstet Gynecol 2006; 107: 511-514

25 Itagaki T, Onodera M, Okuda $N$ et al. Successful use of extracorporeal membrane oxygenation in the reversal of cardiorespiratory failure induced by atonic uterine bleeding: a case report. J Med Case Rep 2014; 8: 23

26 Nair P, Davies AR, Beca J et al. Extracorporeal membrane oxygenation for severe ARDS in pregnant and postpartum women during the 2009 H1N1 pandemic. Intensive Care Med 2011; 37: 648-654

27 Fayad G, Larrue B, Modine T et al. Extracorporeal membrane oxygenation in severe acute respiratory failure in postpartum woman with rheumatic mitral valve disease: benefit, factors furthering the success of this procedure, and review of the literature. J Extra Corpor Technol 2007; 39: 112-116

28 Palanzo DA, Baer LD, El-Banayosy A et al. Successful treatment of peripartum cardiomyopathy with extracorporeal membran oxygenation. Perfusion 2009; 24: 75-79

$29 \mathrm{Ho} C H$, Chen KB, Liu SK et al. Early application of extracorporeal membrane oxygenation in a patient with amniotic fluid embolism. Acta Anaethesiol Taiwan 2009; 47: 99-102

30 Lee AJ, Koyyalamudi PL, Martinez-Ruiz R. Severe transfusion-related acute lung injury managed with extracorporeal membrane oxygenation (ECMO) in an obstetric patient. J Clin Anesth 2008; 20: 549-552

31 Miller ES, Grobman WA. Obstetric outcomes associated with induction of labor after 2 prior cesarean deliveries. Am J Obstet Gynecol 2015; 213: 89.e1-89.e5 